\title{
Hydrous-silicic diamond forming fluids
}

\author{
FABRIZIO NESTOLA, DAVIDE NOVELLA, PAOLO \\ NIMIS, MARTHA G. PAMATO, SOFIA LORENZON AND \\ ANDREA CURTOLO
}

University of Padova

Presenting Author: fabrizio.nestola@unipd.it

Diamonds are extraordinary samples as they can incorporate material from the mantle as deep as $\sim 800 \mathrm{~km}$ [1]. Geoscientists widely agree that diamonds form from $\mathrm{C}$-bearing fluids/melts. However, very little is known about the origin and composition of diamond-forming fluids, limiting our knowledge of the mechanism and environment of diamond formation.

Fluid inclusions found in diamonds are of particular interest as they can provide information about the composition of fluid/melts they were generated from in the deep mantle. The socalled "fibrous diamonds" are those characterized by a high density of sub-micron size fluid inclusions that often overgrow a monocrystalline diamond. These specimens have provided important insights into the composition of fluids forming fibrous diamonds, recognized to be carbonatitic, hydrous-silicic or hydrous-saline [see 1 for a review]. However, different lines of evidence suggested that these fluid inclusions form during recent growth events and may not be representative for the fluids forming the older diamonds [e.g., 2]. Unfortunately, fluid inclusions are extremely rare in non-fibrous "monocrystalline diamonds", and studies that investigated them have limitations related, for example, to their unconstrained time of formation or the small size that prevent their accurate analysis $[3,4,5]$.

Hydrous silicic fluid films surrounding mineral inclusions in gem-quality monocrystalline diamonds have been recently discovered and interpreted as being diamond-forming fluids trapped at the inclusion-host interface during diamond formation [6]. These fluid films have been reported around silicates and oxides and in samples with peridotitic and eclogitic paragenesis. As such, these films are possibly the most representative samples to determine the composition of fluids parent to the most soughtafter diamonds. This presentation will provide an overview on the current knowledge of fluid films found around inclusions in diamonds and discuss their significance in the genesis of diamonds.

[1] Shirey et al. (2013), Review in Mineralogy and Petrology $75,355-421$

[2] Gurney et al. (2010), Economic Geology 105, 689-712

[3] Smith et al. (2015) Lithos 216-217, 106-117

[4] Logvinova et al. (2011), Russian Geology and Geophysics $52,1286-1297$

[5] Jablon \& Navon (2016), Earth and Planetary Science Letters 443, 41-47

[6] Nimis et al. (2016), Lithos 260, 384-389 